\title{
KINETICS STUDY OF Au(III) ADSORPTION ON GALLIC ACID INTERCALATED Mg/Al-HYDROTALCITE
}

\author{
Ika Yanti ${ }^{a}$, Sri Juari Santosa ${ }^{b}$, Indriana Kartini ${ }^{b}$ \\ ${ }^{a}$ Program Studi Kimia, Fakultas Matematika dan Ilmu Pengetahuan Alam, Universitas \\ Islam Indonesia, Jl. Kaliurang Km. 14,5 Sleman Yogyakarta 55584 Indonesia \\ Email: ika.success90@gmail.com \\ ${ }^{b}$ Jurusan Kimia, Fakultas Matematika dan Ilmu Pengetahuan Alam, Universitas Gadjah \\ Mada, Sekip Utara, Bulaksumur, Yogyakarta, 55281 Indonesia
}

\begin{abstract}
ABSTRAK
Studi kinetika adsorpsi $\mathrm{Au}(\mathrm{III})$ pada $\mathrm{Mg} / \mathrm{Al}$-Hidrotalsit (Mg/Al-HT) terinterkalasi asam galat (AG) dilakukan dengan cara interaksi antara larutan $\mathrm{Au}(\mathrm{III})$ dalam spesies $\mathrm{AuCl}_{4}{ }^{-}$dengan sejumlah Mg/Al-HT-AG yang disintesis melalui metode kopresipitasi langsung (direct synthesis). Parameter yang digunakan dalam penentuan kinetika adsorpsi adalah variasi waktu kontak dan untuk untuk penentuan isoterm adsorpsi dilakukan variasi konsentrasi $\mathrm{Au}(\mathrm{III})$ dengan waktu kontak optimum. Analisis kandungan $\mathrm{Au}(\mathrm{III})$ yang tidak teradsorpsi pada adsorben $\mathrm{Mg} / \mathrm{Al}-\mathrm{HT}$ terinterkalasi AG dilakukan analisis dengan AAS. Adsorpsi Au(III) oleh Mg/Al-HT terinterkalasi AG yang berlangsung pada $\mathrm{pH} 3$ mengikuti model kinetika pseudo orde dua dengan konstanta laju (k) $3,798 \times 10^{-4}$ g. $\mathrm{mg}^{-1}$.menit ${ }^{-1}$ serta model isoterm adsorpsimengikuti model isoterm Langmuir dengan kapasitas adsorpsi $\left(\mathrm{q}_{\text {maks }}\right) 625 \mathrm{mg} \cdot \mathrm{g}^{-1}$.
\end{abstract}

Kata kunci: Kinetika; isoterm; hidrotalsit; adsorpsi; $\mathrm{Au}(\mathrm{III})$

\begin{abstract}
Kinetics study of $\mathrm{Au}(\mathrm{III})$ adsorption on gallic acidintercalated $\mathrm{Mg} / \mathrm{Al}$-hydrotalcite (Mg/Al$\mathrm{HT}$ ) is conducted by means of interacting between the $\mathrm{Au}(\mathrm{III})$ solution with $\mathrm{AuCl}_{4}$ 'species with GA intercalated $\mathrm{Mg} / \mathrm{Al}-\mathrm{HT}$ synthesized by direct coprecipitation method.The parameters used in the determination of adsorption kinetics is varied contact time of adsorption and for the determination of adsorption isotherm the varied $\mathrm{Au}(\mathrm{III})$ concentration at optimum contact time was used. Analysis of $\mathrm{Au}(\mathrm{III})$ in rest solution was performed by AAS. The adsorption of $\mathrm{Au}(\mathrm{III})$ byGA intercalated $\mathrm{Mg} / \mathrm{Al}-\mathrm{HT}$ was optimum at $\mathrm{pH} 3$ and followed pseudo-second order kinetic and Langmuir isoterm models with rate constant $(\mathrm{k})$ and adsorption capacity were $3.798 \times 10^{-4} \mathrm{~g} . \mathrm{mg}^{-}$ ${ }^{1}$.minute ${ }^{-1}$ and $625 \mathrm{mg} . \mathrm{g}^{-1}$,respectively.
\end{abstract}

Keywords: Kinetic; isotherm; hydrotalcite; adsorption, $\mathrm{Au}(\mathrm{III})$

\section{Pendahuluan}

Material clay merupakan material hidroksida berlapis yang banyak diaplikasikan diberbagai bidang. Salah satu jenis material clay yang banyak dimanfaatkan sebagai adsorben adalah hidrotalsit (Cavani dkk., 1991). Adsorben hidrotalsit telah banyak dikaji oleh peneliti khususnya untuk adsorpsi ion logam dalam larutan. Ion logam yang biasa digunakan dalam adsorpsi menggunakan adsorben hidrotalsit adalah ion logam emas (Au(III)) (Ikhsan, 2011; Fitriani, 2013; Hidaiyanti, 2013; Elianasari, 2015). 
Studi kinetika dan isoterm adsorpsi pada adsorben merupakan parameter penting untuk mengetahui karakteristik dari suatu adsorben dalam menentukan laju dan kapasitas adsorpsi suatu adsorbat pada permukaan adsoben (Holle dkk., 2013). Studi kinetika dan isoterm adsorpsi juga dapat untuk mengetahui energi yang dihasilkan akibat proses adsorpsi suatu adsorbat pada permukaan adsorben sehingga dapat diketahui interaksi antara adsorbat dengan adsorben apakah interaksinya secara fisika atau kimia. Pengetahuan mengenai interaksi fisika dan kimia dapat digunakan untuk memprediksi proses desorpsi adsorbat pada permukaan adsorben.

Model kinetika adsorpsi yang biasa digunakan untuk studi kinetika antara lain adalah model kinetika Langmuir-Hinshelwood, Santosa, Lagergreen dan Ho. Model kinetika Langmuir-Hinshelwood (1) merupakan model kinetika dengan mengasumsikan bahwa konsentrasi mula-mula dari suatu adsorbat $\left(\mathrm{C}_{0}\right)$ mempengaruhi laju adorpsi sedangkan untuk model kinetika Santosa (2) mengasumsikan bahwa konsentrasi awal adsorbat $\left(\mathrm{C}_{0}\right)$ tidak mempengaruhi jalannya laju reaksi dan yang mempengaruhi adalah konsentrasi adsorbat pada keadaan $\mathrm{t}$ tertentu $\left(\mathrm{C}_{\mathrm{A}}\right)$ (Santosa dkk., 2007).

$$
\begin{aligned}
& \frac{\ln \frac{\mathrm{C}_{0}}{\mathrm{C}_{\mathrm{A}}}}{\mathrm{C}_{0}-\mathrm{C}_{\mathrm{A}}}+\mathrm{K}=\frac{\mathrm{k} \cdot \mathrm{t}}{\mathrm{C}_{0}-\mathrm{C}_{\mathrm{A}}} \\
& \frac{\ln \frac{\mathrm{C}_{0}}{\mathrm{C}_{\mathrm{A}}}}{\mathrm{C}_{\mathrm{A}}}=\frac{\mathrm{k} \cdot \mathrm{t}}{\mathrm{C}_{\mathrm{A}}}+\mathrm{K}
\end{aligned}
$$

Di mana $\mathrm{K}$ adalah Konstanta kesetimbangan dan $\mathrm{k}$ adalah konstanta laju adsorpsi. Model kinetika Lagergreen menyatakan bahwa kinetika adsorpsi didasarkan pada kapasitas adsorpsi pada suatu fasa padatan yang dinyatakan dengan pseudo orde satu (3) sedangkan model kinetika Ho dinyatakan sebagai pseudo orde dua (4).

$$
\begin{aligned}
& \log \left(\mathrm{q}_{\mathrm{e}}-\mathrm{q}_{\mathrm{t}}\right)=\log \mathrm{q}_{\mathrm{e}}-\left(\frac{\mathrm{k}}{2,303}\right) \\
& \frac{\mathrm{t}}{\mathrm{q}_{\mathrm{t}}}=\frac{1}{\mathrm{~h}}+\frac{1}{\mathrm{q}_{\mathrm{e}}} \mathrm{t}
\end{aligned}
$$

Di mana $\mathrm{q}_{\mathrm{e}}$ merupakan kapasitas adsorpsi pada saat kesetimbangan, $q_{t}$ adalah kapasitas adsorpsi pada saat $\mathrm{t}$ tertentu, $\mathrm{h}$ merupakan laju adsorpsi awal dan $\mathrm{h}$ dinyatakan sebagai $\mathrm{h}=\mathrm{kq}_{\mathrm{e}}{ }^{2}(\mathrm{Ho}, 2006)$.

Model isoterm adsorpsi yang dapat menggambarkan pola adsorpsi adsorbat pada permukaan adsorben biasanya dengan menggunakan model isoterm Langmuir dan Freundlich. Model isoterm adsorpsi Langmuir (4) didasarkan pada asumsi bahwa energi adsorpsi tergantung pada penutupan situs aktif pada adsorben yang mana situs aktif pada adsorben tersebut bersifat homogen sehingga 
apabila situs aktif telah tertutup adsorbat menyebabkan adsorben hanya akan mampu membentuk satu lapisan adsorbat (monolayer) pada permukaannya (Oscik, 1982).

$$
\frac{\mathrm{C}_{\mathrm{e}}}{\mathrm{q}_{\mathrm{e}}}=\frac{1}{\mathrm{q}_{\text {maks }} \mathrm{K}_{\mathrm{L}}}+\frac{\mathrm{C}_{\mathrm{e}}}{\mathrm{q}_{\text {maks }}}
$$

Model isoterm adsorpsi Freundlich (5) didasarkan pada asumsi bahwa energi adsorpsi tergantung pada interaksi adsorbat dengan permukaan adsorben yang bersifat heterogen (Oscik, 1982). Heterogenitas permukaan adsorben tersebut dapat disebabkan karena perbedaan kekuatan situs aktif pada permukaan adsorben akibat adanya gugus fungsi yang berbeda yang diikat oleh adsorben. Heterogenitas permukaan adsorben tersebut dapat menyebabkan interaksi antara situs aktif satu dan yang lain dengan molekul adsorbat juga berbeda sehingga permukaan adsorbat yang terikat pada permukaan adsorben dapat membentuk lebih dari satu lapisan (multilayer).

$$
\log \mathrm{q}_{\mathrm{e}}=\log \mathrm{K}_{\mathrm{F}}-\frac{1}{\mathrm{n}} \log \mathrm{C}_{\mathrm{e}}
$$

\section{Tujuan Penelitian}

Penelitian ini bertujuan:

1. Mempelajari kinetika adsorpsi Au(III) oleh $\mathrm{Mg} / \mathrm{Al}-\mathrm{HT}$ terinterkalasi asam galat.
2. Menentukan model isotherm dan kapasitas adsorpsi $\mathrm{Au}(\mathrm{III})$ oleh $\mathrm{Mg} / \mathrm{Al}-$ HT terinterkalasi asam galat.

\section{Bahan dan Metode Penelitian}

\section{Bahan}

Bahan yang digunakan dalam penelitian ini adalah bahan-bahan berkualitas pro analyze (p.a) seperti $\mathrm{Mg}\left(\mathrm{NO}_{3}\right)_{2} \cdot 6 \mathrm{H}_{2} \mathrm{O}, \quad \mathrm{Al}\left(\mathrm{NO}_{3}\right)_{3} \cdot 9 \mathrm{H}_{2} \mathrm{O}$ dan $\mathrm{NaOH}$ semua bahan tersebut produksi Emerck danasam galat $\left(\mathrm{C}_{7} \mathrm{H}_{6} \mathrm{O}_{5} \cdot \mathrm{H}_{2} \mathrm{O}\right)$ produksi Sigma-Aldrich. Larutan Au(III) 1000 ppm, kertas saring Whatman 42 dan gas $\mathrm{N}_{2}$ (CV. Perkasa), akuades dan akuabides (laboratorium Kimia Dasar FMIPA UGM) dan akuademineral (CV. Bratachem),

\section{Metode}

Sintesis Mg/Al-HT terinterkalasi AG melalui metode kopresipitasi langsung dengan konsentrasi molar $\mathrm{Mg}^{2+}: \mathrm{Al}^{2+}: \mathrm{AG}$ $(2: 1: 0,5)$. Campuran dibuat dalam kondisi basa dengan menambahkan larutan $\mathrm{NaOH}$ 0,5 M sambil dialiri gas $\mathrm{N}_{2}$ sampai $\mathrm{pH}=9$ dan campuran dijaga selama 30 menit sambil diaduk. Campuran kemudian dilakukan hidrotermal pada suhu $120^{\circ} \mathrm{C}$ selama 5 jam, selanjutnya didinginkan hingga proses pengendapan sempurna. Endapan dipisahkan dari larutannya dengan cara centrifugation. Endapan yang diperoleh dicuci dengan akuades bebas 
$\mathrm{CO}_{2}$ hingga $\mathrm{pH}$ netral. Endapan yang berupa koloid masih mengandung air tersebut selanjutnya disari dengan kertas Whatman no. 42 dan dikeringkan dalam oven pada suhu $70{ }^{\circ} \mathrm{C}$ selama 48 jam. Setelah kering padatan yang diperoleh digerus dengan lumpang porselen. Karakterisasi padatan hasil sintesis dilakukan dengan spektrofotometer inframerah (Fourier Transform Infra-Red/ FTIR), Shimadzu Prestige-21.

AdsorbenMg/Al-HT terinterkalasi AG hasil sintesis kemudian dilakukan penentuan laju dan model isotherm adsorpsi $\mathrm{Au}(\mathrm{III})$ untuk mengetahui model kinetika dan model adsorpsi yang sesuai serta dapat menentukan kapasitas adsorpsi maksimum $\mathrm{Au}(\mathrm{III})$. Pada penentuan model kinetika adsorpsi $\mathrm{Au}(\mathrm{III})$ oleh $\mathrm{Mg} / \mathrm{Al}-\mathrm{HT}$ terinterkalasi AG, dilakukan serangkaian proses adsorpsi dengan variasi waktu kontak $0,10,20,30,60,90$, 120, 150, 200, 250, 300 dan 350 menit pada kondisi pH 3 di mana berat adsorben yang digunakan sebanyak $10 \mathrm{mg}$ dan dan larutan $\mathrm{Au}(\mathrm{III})$ sebanyak $10 \mathrm{~mL}$ dengan konsentrasi awal $500 \mathrm{mg} . \mathrm{L}^{-1}$ setelah itu campuarn disaring dengan kertas saring Whatman 42. Kadar Au(III) diukur dengan spektrometer Atomic Absorption Spectroscopy (AAS, Perkin Elmer 3110). Model isoterm adsorpsi Au(III) dilakukan dengan serangkaian proses yaitu dengan variasi konsentrasi larutan $\mathrm{Au}(\mathrm{III})$ 0, 100,
200, 400, 600, 800 dan 1000 mg.L L $^{-1}$ pada kondisi $\mathrm{pH} 3$, kemudian campuran digojog pada waktu optimum, setelah itu campuran disaring dengan kertas saring Whatman 42. Konsentrasi Au(III) sisa dalam larutan diukur dengan AAS.

\section{Hasil dan Pembahasan}

\section{Karakterisasi adsorben Mg/Al-HT} terinterkalasi AG

Adsorben $\mathrm{Mg} / \mathrm{Al}-\mathrm{HT}-\mathrm{AG}$ yang disintesis dengan metode direct synthesis pada $\mathrm{pH}=9$ dianalisis dengan spektrofotometer FTIR yang kemudian dibandingkan dengan adsorben yang disintesis melalui metode indirect synthesis. Karakaterisasi tersebut bertujuan untuk mengetahui terjadinya interkalasi asam galat (AG) pada adsorben $\mathrm{Mg} / \mathrm{Al}-\mathrm{HT}$.

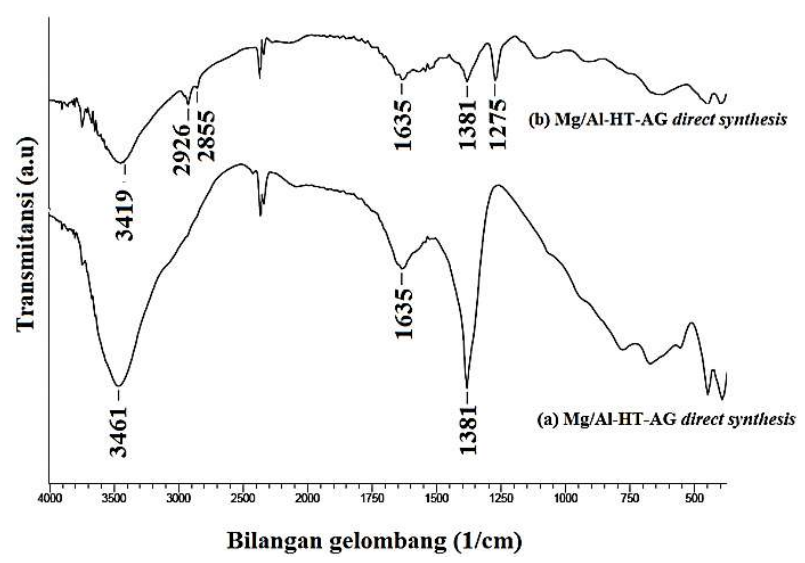

Gambar 1. Spektra FTIR Mg/Al-HT-AG yang disintesis melalui (a) indirect synthesis dan (b) direct synthesis

Berdasarkan Pada Gambar 1dapat disimpulkan bahwa AG telah terinterkalasi pada daerah interlayer 
Mg/Al-HT. Hal tersebut dapat diketahui dengan menurunnya puncak serapan pada bilangan gelombang 3461, 1635 dan 1381 $\mathrm{cm}^{-1}$ yang merupakan vibrasi stretching dan bending dari $\mathrm{O}-\mathrm{H}$ (molekul $\mathrm{H}_{2} \mathrm{O}$ dan anion $\mathrm{OH}^{-}$) serta vibrasi stretching $\mathrm{N}-\mathrm{O}$ dari $\mathrm{NO}_{3}{ }^{-}$(anion interkalat). Intensitas yang menurun tersebut disebabkan karena gugus maupun molekul tersebut telah tergantikan oleh keberadaan anion AG. Intensitas yang menunjukkan keberadaan anion AG adalah munculnya puncak serapan baru pada 2855 dan $2926 \mathrm{~cm}^{-1}$ yang diduga merupakan vibrasi stretching dari $\mathrm{C}-\mathrm{H} \mathrm{sp}^{2}$ dan $\mathrm{sp}^{3}$. Munculnya puncak tersebut dikarenakan anion $\mathrm{AG}$ merupakan senyawa fenolik yang mengandung $\mathrm{C}-\mathrm{H} \mathrm{sp}^{2}$ dan kemungkinan mengalami oksidasi membentuk quinon sehingga $\mathrm{C}-\mathrm{H} \quad \mathrm{sp}^{2}$ menjadi $\mathrm{C}-\mathrm{H} \quad \mathrm{sp}^{3}$. Serapan baru pada $1275 \mathrm{~cm}^{-1}$ merupakan vibrasi stretching $\mathrm{C}-\mathrm{O}$ dari anion $\mathrm{AG}$ sehingga dapat disimpulkan bahwa anion AG telah masuk pada daerah interlayer $\mathrm{Mg} / \mathrm{Al}-\mathrm{HT}$ dengan cara menggantikan posisi anion nitrat $\left(\mathrm{NO}_{3}{ }^{-}\right)$yang berasal dari anion precursor logam pembentuk framework hidrotalsit.

\section{Kinetika adsorpsi Au(III) pada Mg/Al-}

HT terinterkalasi AG

Berdasarkan hasil penelitian yang ditunjukkan oleh Gambar 2 kesetimbangan adsorpsi $\mathrm{Au}(\mathrm{III})\left(\mathrm{q}_{\mathrm{e}}\right)$ oleh
$\mathrm{Mg} / \mathrm{Al}-\mathrm{HT}$ terinterkalasi AG terjadi pada menit ke 150 (2,5 jam). Setelah kesetimbangan tercapai, seiring bertambahnya waktu masih terjadi kenaikan adsorpsi $\mathrm{Au}(\mathrm{III})$ akan tetapi kenaikan adsorpsi $\mathrm{Au}(\mathrm{III})$ setelah menit ke 150 tidak signifikan sehingga disimpulkan bahwa waktu kesetimbangan adsorpsinya berada pada menit ke 150 .

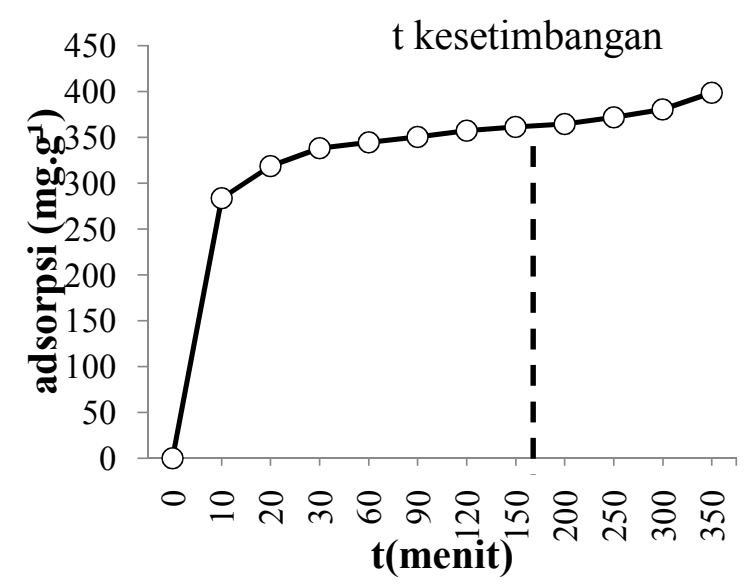

Gambar 2. Pengaruh waktu terhadap adsorpsi $\mathrm{Au}(\mathrm{III})$ oleh $\mathrm{Mg} / \mathrm{Al}-\mathrm{HT}$ terinterkalasi $\mathrm{AG}$

Kinetika adsorpsi $\mathrm{Au}(\mathrm{III})$ oleh $\mathrm{Mg} / \mathrm{Al}-\mathrm{HT}$ terinterkalasi AG dipelajari dengan menggunakan beberapa pendekatan model, yaitu model kinetika Langmuir-Hinshelwood, Lagergreen, Santosa dan Ho.

Model kinetika Langmuir-Hinshelwood dilakukan dengan membuat kurva linear:

$$
\frac{\ln \frac{\mathrm{C}_{0}}{\mathrm{C}_{\mathrm{A}}}}{\mathrm{C}_{0}-\mathrm{C}_{\mathrm{A}}} \mathrm{vs} \frac{\mathrm{t}}{\mathrm{C}_{0}-\mathrm{C}_{\mathrm{A}}}
$$

dengan slope sebagai nilai $\mathrm{k}$ dan intersep adalah nilai K. Model kinetika Santosa dilakukan dengan membuat kurva linear: 


$$
\frac{\ln \frac{\mathrm{C}_{0}}{\mathrm{C}_{\mathrm{A}}}}{\mathrm{C}_{\mathrm{A}}} \mathrm{vs} \frac{\mathrm{t}}{\mathrm{C}_{\mathrm{A}}}
$$

dengan slope sebagai nilai $\mathrm{k}$ dan intersep adalah nilai K. Model kinetika Lagergreen (pseudo orde satu) dilakukan dengan membuat kurva linear:

$$
\log \left(q_{e}-q_{t}\right) \text { vs } t
$$

dengan slope sebagai nilai $\left(\frac{\mathrm{k}}{2,303}\right)$ dan intersep adalah nilai $\log \mathrm{q}_{\mathrm{e}}$. Model kinetika pseudo orde dua yang dikemukakan oleh Ho dilakukan dengan membuat kurva linear:

$$
\frac{\mathrm{t}}{\mathrm{q}_{\mathrm{t}}} \mathrm{vs} \mathrm{t}
$$

dengan slope sebagai nilai nilai $\frac{1}{\mathrm{q}_{\mathrm{e}}}$ dan intersep adalah nilai $\frac{1}{\mathrm{~h}}$, di mana $\mathrm{h}=\mathrm{kq}_{e}{ }^{2}$
Berdasarkan Tabel 1 mengenai perhitungan parameter kinetika adsorpsi dari keempat model kinetika adsorpsi yang dipelajari, model kinetika Ho yang memberikan nilai linearitas $\left(\mathrm{R}^{2}\right)$ yang paling baik $\left(\mathrm{R}^{2} \approx 1\right)$ dibandingkan model kinetika Langmuir-Hinshelwood, Santosa dan Lagergreen. Dengan demikian proses adsorpsi $\mathrm{Au}(\mathrm{III})$ oleh $\mathrm{Mg} / \mathrm{Al}-\mathrm{HT}$ terinterkalasi AG lebih mengikuti model kinetika pseudo orde dua Ho, dengan konstanta laju adsorpsi $3,798 \times 10^{-4}$ g.mg${ }^{1}$.menit $^{-1}$ yang berarti $3,798 \times 10^{-4} \mathrm{~g}$ adsorben mampu mengadsorpsi 1,0 $\mathrm{mg}$ adsorbat dalam 1 menit. Hal ini menyatakan secara tidak langsung bahwa faktor yang mempengaruhi laju adsorpsi $\mathrm{Au}(\mathrm{III})$ oleh Mg/Al-HT terinterkalasi AG adalah konsentrasi dari adsorbat dan situs aktif dari adsorben tersebut.

\begin{tabular}{|c|c|c|c|c|}
\hline \multirow{2}{*}{$\begin{array}{c}\text { Model } \\
\text { Kinetika }\end{array}$} & \multicolumn{4}{|c|}{ Parameter Kinetika } \\
\hline & $\mathbf{R}^{2}$ & $\mathbf{k}$ & $\mathbf{K}$ & h \\
\hline $\begin{array}{l}\text { Langmuir- } \\
\text { Hinshelwood }\end{array}$ & 0,7553 & $0,108 \times 10^{3}$ menit $^{-1}$ & $\begin{array}{c}1,1359 \times 10^{3} \\
\text { L. } \mathrm{mol}^{-1}\end{array}$ & - \\
\hline Santosa & 0,8385 & $0,401 \times 10^{3}$ menit $^{-1}$ & $\begin{array}{c}1,9241 \times 10^{3} \\
\text { L.mol }{ }^{-1}\end{array}$ & - \\
\hline Lagergreen & 0,6879 & $6,6787 \times 10^{-3}$ menit $^{-1}$ & - & - \\
\hline Ho & 0,9974 & $3,798 \times 10^{-4}$ g. $\mathrm{mg}^{-1} \cdot$ menit $^{-1}$ & - & $\begin{array}{c}56,179 \\
\mathrm{mg} \cdot \mathrm{g}^{-1} \cdot \mathrm{menit}^{-1}\end{array}$ \\
\hline
\end{tabular}

Tabel 1. Hasil perhitungan kinetika adsorpsi $\mathrm{Au}(\mathrm{III})$ oleh $\mathrm{Mg} / \mathrm{Al}-\mathrm{HT}$ terinterkalasi AG dengan menggunakan berbagai model

Isoterm adsorpsi $\mathrm{Au}(\mathrm{III})$ pada $\mathrm{Mg} / \mathrm{Al}-$

\section{HT terinterkalasi AG}

Kapasitas adsorpsi $\mathrm{Au}(\mathrm{III})$ oleh $\mathrm{Mg} / \mathrm{Al}-\mathrm{HT}$ terinterkalasi AG ditentukan melalui pendekatan model isoterm adsorpsi Freundlich dan Langmuir. Penentuan adsorpsi $\mathrm{Au}(\mathrm{III})$ oleh $\mathrm{Mg} / \mathrm{Al}-$ HT terinterkalasi AG dengan model isoterm Freundlich dilakukan dengan membuat kurva linier antara $\log \mathrm{q}_{\mathrm{e}} \mathrm{vs} \log$ 
$\mathrm{C}_{\mathrm{e}}$, sedangkan model isoterm Langmuir dilakukan dengan membuat kurva linier antara $\mathrm{C}_{\mathrm{e}} / \mathrm{q}_{\mathrm{e}}$ vs $\mathrm{C}_{\mathrm{e}}$. Berdasarkan persamaan model isoterm Freundlich dan Langmuir diperoleh tabel perbandingan parameter model isoterm tersebut yang ditunjukkan oleh Tabel 2.

Tabel 2. Parameter isoterm adsorpsi Freundlich dan Langmuir pada proses adsorpsi $\mathrm{Au}(\mathrm{III})$ oleh $\mathrm{Mg} / \mathrm{Al}-\mathrm{HT}$ terinterkalasi AG

\begin{tabular}{lcc}
\hline \multirow{2}{*}{ Parameter } & \multicolumn{2}{c}{ Model isoterm } \\
\cline { 2 - 3 } & Freundlich & Langmuir \\
\hline $\mathbf{R}^{2}$ & 0,7827 & 0,8837 \\
$\mathbf{K}$ & $59,224 \mathrm{mg} \cdot \mathrm{g}^{-}$ & $7,637 \times 10^{-3}$ \\
& ${ }^{2}\left(\mathrm{~K}_{\mathrm{F}}\right)$ & $\mathrm{L} \cdot \mathrm{mg}^{-1}\left(\mathrm{~K}_{\mathrm{F}}\right)$ \\
$\mathbf{n}$ & 2,957 & - \\
$\mathbf{q}_{\text {maks }}$ & - & $625 \mathrm{mg} \cdot \mathrm{g}^{-1}$ \\
\hline
\end{tabular}

Pada Tabel 2 diketahui bahwa proses adsorpsi $\mathrm{Au}(\mathrm{III})$ oleh $\mathrm{Mg} / \mathrm{Al}-\mathrm{HT}$ terinterkalasi AG lebih mengikuti model isoterm Langmuir dengan nilai $\mathrm{R}^{2}$ sebesar 0,8837. Berdasarkan model isoterm Langmuir tersebut maka permukaan adsorben $\mathrm{Mg} / \mathrm{Al}-\mathrm{HT}-\mathrm{AG}$ bersifat homogen yang menyebabkan adsorpsi $\mathrm{Au}(\mathrm{III})$ pada permukaan $\mathrm{Mg} / \mathrm{Al}-\mathrm{HT}$ terinterkalasi AG hanya membentuk satu lapisan (monolayer) adsorbat pada permukaan situs aktif adsorben. Hal tersebut disebabkan karena situs-situs aktif pada adsorben memiliki energi adsorpsi yang sama terhadap adsorbat sehingga hanya akan mampu membentuk lapisan monolayer adsorbat.
Berdasarkan perhitungan menurut model isoterm Langmuir diperoleh kapasitas Mg/Al-HT terinterkalasi AG untuk mengadsorpsi $\mathrm{Au}(\mathrm{III})$ adalah sebesar $625 \mathrm{mg} \cdot \mathrm{g}^{-1}$, artinya satu gram adsorben $\mathrm{Mg} / \mathrm{Al}-\mathrm{HT}$ terinterkalasi AG mampu mengadsorpsi $\mathrm{Au}(\mathrm{III})$ sebesar 625 mg dengan nilai $K_{L}$ sebesar $7,637 \times 10^{-3}$ L.mg ${ }^{-1}$. Hal tersebut menandakan bahwa adsorben $\mathrm{Mg} / \mathrm{Al}-\mathrm{HT}$ terinterkalasi $\mathrm{AG}$ yang disintesis melalui reaksi insitu (direct synthesis) dengan metode kopresipitasi langsung memiliki kapasitas adsorpsi yang lebih besar dibandingkan dengan adsorben $\mathrm{Mg} / \mathrm{Al}-\mathrm{HT}$ terinterkalasi AG yang dibuat melalui indirect synthesis yang dilakukan oleh Fitriani (2013) yang hanya memiliki kapasitas adsorpsi sebesar 125 mg.g ${ }^{-1}$. Reaksi insitu (direct synthesis) dari sintesis Mg/Al-HT terinterkalasi AG merupakan sintesis $\mathrm{Mg} / \mathrm{Al}-\mathrm{HT}$ terinterkalasi AGmelalui metode kopresipitasi langsung dengan cara mereaksikan prekursor logam dengan modifier (AG) secara bersamaan sehingga terjadi reaksi secara in situ sedangkan indirect synthesis pada pembuatan adsorben $\mathrm{Mg} / \mathrm{Al}-\mathrm{HT}$ yang termodifikasi AG merupakan sintesis modifikasi adsorben $\mathrm{Mg} / \mathrm{Al}-\mathrm{HT}$ dengan AG melalui mekanisme ion exchange antara ion interkalat pada $\mathrm{Mg} / \mathrm{Al}-\mathrm{HT}$ dengan ion $\mathrm{AG}$ (Aguzzi dkk., 2007). 
Energi adsorpsi $\mathrm{Au}(\mathrm{III})$ oleh $\mathrm{Mg} / \mathrm{Al}-\mathrm{HT}$ terinterkalasi AG sebesar $19,43 \times 10^{3} \mathrm{~J} \mathrm{~mol}^{-1}$ yang reaksinya bersifat exergonic. Metode kopresipitasi langsung dengan reaksi insitu (direct synthesis) memiliki keunggulan dibandingkan dengan indirect synthesis karena proses sintesis tidak membutuhkan waktu yang lama, prosesnya mudah, penggunaan reagen $\mathrm{NaOH}$ yang sedikit, namun mampu menghasilkan adsorben yang efektif yang memiliki kapasitas adsorpsi $\mathrm{Au}(\mathrm{III})$ yang lebih besar.

\section{Kesimpulan}

Kesimpulan dari penelitian ini adalah:

1. Adsorpsi $\mathrm{Au}(\mathrm{III})$ oleh asorben $\mathrm{Mg} / \mathrm{Al}$ HT terinterkalasi AG pada konsisi $\mathrm{pH}_{\mathrm{adsorpsi}}=3$ mengikuti model kinetika pseudo orde dua Ho dengan konstanta laju (k) $3,798 \times 10^{-4}$ g.mg ${ }^{-1} \cdot$ menit $^{-1}$.

2. Adsorpsi $\mathrm{Au}(\mathrm{III})$ oleh asorben $\mathrm{Mg} / \mathrm{Al}-$ HT terinterkalasi AGpada kondisi $\mathrm{pH}_{\text {adsorpsi }}=3$ mengikuti model isoterm adsorpsi Langmuir dengan kapasitas adsorpsi ( $\left.\mathrm{q}_{\text {maks }}\right) 625 \mathrm{mg} \cdot \mathrm{g}^{-1}$.

\section{Ucapan Terima Kasih}

Penulis mengucapkan terima kasih kepada Direktur Jenderal Pendidikan Tinggi atas bantuan dana untuk penelitian ini melalui Beasiswa Program Pascasarjana Dalam Negeri (BPPDN) tahun anggaran 2013-2015.

\section{Daftar Pustaka}

Aguzzi, A., Ambrogi, V., Costantino, U., and Marmottini, F., 2007, Intercalation of acrylate anions into the galleries of $\mathrm{Zn}$-Al layered double hydroxide, J.Phys. Chem., $68,808-812$.

Cavani, F., Trifiri, F., and Vaccari, A., 1991, Hydrotalcite-type Anionic Clay:Preparation, Properties and Application, Catal. Today, 11, 173-301.

Elianasari, 2015, Modifikasi $\mathrm{Mg} / \mathrm{Al}$ Hidrotalsit dengan Asam Galat dan Aplikasinya untuk AdsorpsiReduksi $\mathrm{AuCl}_{4}{ }^{-}$, Tesis, Universitas Gadjah Mada, Yogyakarta.

Fitriani, D., 2013, Immobilisasi Asam Galat pada $\mathrm{Mg} / \mathrm{Al}$ Hidrotalsit danAplikasinya untuk Removal $\mathrm{AuCl}_{4}^{-}$, Tesis, Universitas Gadjah Mada, Yogyakarta.

Hidaiyanti, R., 2013, Immobilisasi Asam Askorbat pada $\mathrm{Mg} / \mathrm{Al}$ Hidrotalsit dan Aplikasinya untuk Adsorpsi Reduksi $\mathrm{AuCl}_{4}^{-}$, Tesis, Universitas Gadjah Mada, Yogyakarta.

Ho, Y.S., 2006, Review of Second order Models for Adsorption System, $J$. Hazard. Mater., 36, 681-689.

Holle, R.B., Wuntu, A.D. dan Sangi, M.S., 2013, Kinetika Adsorpsi Gas Benzena pada Karbon Aktif 
Tempurung Kelapa, Jurnal MIPA

UNSRAT Online, 2(2), 100-104.

Ikhsan, N,A., 2011, Kajian Adsorpsi

Desorpsi $\left[\mathrm{AuCl}_{4}\right]^{-}$pada $\mathrm{Mg} / \mathrm{Al}$

Hidrotalsit, Tesis, Universitas

Gadjah Mada, Yogyakarta.

Oscik, J., 1982, Adsorption, 1st ed., John Wiley \& Sons, New York.

Santosa, S.J., Siswanta, D., Kurniawan, and A., Rahmanto, W.H., 2007, Hybrid of Chitin and Humic Acid as High Performance Sorbent for Ni(II), Surf.Sci., 601, 5155-5161. 